Original Article

\title{
Awareness regarding body and organ donation amongst the population of an urban city in India
}

\author{
Vaishaly K. Bharambe ${ }^{1}$, Rathod H. ${ }^{2}$, Paranjape V. M. ${ }^{3}$, Kanaskar N. ${ }^{4}$, Shevade S. ${ }^{5}$, Survase K. ${ }^{6}$, \\ Arole V. ${ }^{7}$, Singh Sakshi ${ }^{8}$, Brahmbhatt Gaurav ${ }^{9} \&$ Alam Feroz ${ }^{10}$ \\ ${ }^{1,3}$ Associate Professors, ${ }^{4,5}$ Assistant Professors, ${ }^{7}$ Professor \& HOD, Department of Anatomy, ${ }^{2}$ Associate Professor, \\ Department of Preventive Medicine, ${ }^{6}$ Organ transplant co-ordinator, Department of Nephrology, \\ ${ }^{8,9,10}$ Interns, Dr. D.Y. Patil M edical College \& Research Centre, Pune, India.
}

\author{
Correpondence \\ Vaishaly K. Bharambe \\ D-9 State Banknagar, Panchvati, Pashan Road, Pune - 411 008, M aharashtra, India. \\ M obile : +919822910845 E-mail : vaishalybharambe@yahoo.co.in
}

\section{Abstract}

Purpose : Bodies for purpose of dissection and organs for transplantation surgeries are needed for education of medical students and treatment of cases of end-stage organ failure. However deceased organ donation rate in India is very dismal. In the present study the authors assess the knowledge and attitude of the people living in an urban city in India towards organ and body donation.

\begin{abstract}
Materials/Methods : A questionnaire was distributed amongst all willing patients and their relatives attending the out-patient Department at our Hospital. This was followed by an awareness session wherein the researchers discussed body and organ donation and its need in India. Information sheet was handed to all and the willing respondents were given eye and body donation forms, and donorcards.
\end{abstract}

Results : $41 / 65$ people consented to participate. $41.5 \%, 31.7 \%, 12.2 \%$ and $12.2 \%$ had obtained knowledge regarding organ donation from newspaper, television, family members and internet respectively. $26.8 \%$ claimed that they were imparted knowledge by health care professionals. $78 \%, 53.7 \%$ and $19.5 \%$ were aware about eye, kidney and liver donations respectively. $17.1 \%$ were aware of body and lung donation each. Awareness of donation of other organs was found to be in the range between $4.9 \%$ to $14.6 \% .43 .9 \%$ were willing to be organ donors and 3 persons filled the body donation forms.

Conclusions : Newspapers, healthcare professionals could be utilized to further the awareness regarding body and organ donation. Carrying out awareness programmes will help to reach information to each individual, clarifying any myths and increasing understanding and motivation levels among

Keywords: Organ donation, body donation, awareness, donor card, donation forms

\section{Introduction}

Today Organ Transplantation is a major treatment protocol for a number of cases of end stage organ failure.[1] However organs procured by organ donation have to be available for such transplantation surgeries to take place. Organ donation and subsequent transplant not only gives the patient a new lease to life but also saves them a lot of

\begin{tabular}{|c|}
\hline Access this article online \\
\hline Quick Response Code \\
\hline
\end{tabular}

expenses which otherwise would have been spent on procedures such as dialysis. While India ranks second in the world in organ transplant surgeries by live organ donors, its deceased organ donation rate is a dismal .08 per million populations per year. [2]

Anatomy is an important subject studied by medical students when they begin their medical career wherein teaching is based on cadaver dissection. Knowledge of anatomy is an indispensable part of the education of health care professionals for which medical students need human bodies for dissection.[3] Donation of human body to medical science is also needed for purpose of research. People have to be aware of these needs and donate their bodies after death so that future health care professionals can study them and learn.

Thusit appears that bodies for purpose of dissection as well as research and organs for organ transplantation surgeries must be available if education of medical science students 
and treatment of cases of end-stage organ failure has to continue.

Alghanim in a community based study compared the knowledge and attitude towards organ donation between urban and rural populations and found that the urban populations were more likely to have information about organ donation, to report willingness to be donors and have knowledge regarding "brain-death". He also states that providing the general public with relevant information and correcting some of the misconceptions are likely to increase the number of individuals willing to donate organs.[4]

In the present study the authors assess the knowledge and attitude of the people living in an urban city in India (Pune,Maharashtra) towards organ and body donation. The authors also discuss the issue of body and organ donation and its necessity in India with the respondents, also providing them with information sheet to take home for discussion with family members.

\section{Methods}

This study was conducted in the Out-patient Department of our Hospital after Ethical clearance. The activity was carried out in two parts. The first part consisted of studying the knowledge and awareness levels of the people attending the out-patient Department in our Hospital, while the second part consisted of discussing body and organ donation with the people and clarifying their do ubts.

\section{Part I}

A specially designed self-administered questionnaire covering demographic data, knowledge and attitude of the participants was prepared by the research team. It was pilot tested on 10 random persons fulfilling the inclusion criteria, who were given a time period of 15 minutes for completion of the questionnaire wherein the respondents would indicate their responses to the questions using the categories provided in the questionnaire in privacy without any discussion with anyone. The questionnaire was thus tested for clarity of the questions as well as time period required for response. Suitable modifications were made in the questionnaire and time span provided.

All patients and their relatives accompanying them were approached to participate in the study. The methodology was explained in detail to them. The inclusion criterion for the study population was age above 18 years and exclusion criterion was those who refused to give consent. Only those consenting to participate were involved in the study. The respondents were assured that their confidentiality would be maintained and ethical principles would be followed.

The pretested questionnaire was administered to all willing patients and their relatives after obtaining their consent. The questionnaire prepared in three languages, i.e. English, Hindi and M arathi was provided to the respondent who was given a choice of language according to his / her comfort level. One of the researchers always stood by the respondents to explain any terms in the questionnaire that they had difficulty in understanding. All explanations were made without influencing the respondents. (Fig 1, 2)

\section{Partll}

After the filled questionnaire was collected back, a discussion was carried out with the respondents about need for organ donation in India in a separate area in the out-patient department. This area had posters of Body and Organ donation on the walls prepared by newly passed out interns* who had completed their final M BBS studies. (fig 2) Any queries regarding the topic of Organ and body donation (whether general or related to some questions in the questionnaire) were clarified. Body and eye donation forms were kept available for those interested in filling them. Information sheet (in Hindi, Marathi and English) containing relevant data on Organ donation was given to respondents as well as to those not willing to participate in the study. This information sheet also contained important phone numbers and addresses of local Hospitals to be contacted for eye or body donation as well as separate numbers to be contacted in case any further clarification was needed by family members at home.

Organ donor cards were handed to those who were willing 
to sign the donor card. In each case, while handing over the donor card, importance of sharing this decision with family members was emphasized.

(*Interns were medical students who had just passed their final year of MBBS and were undergoing their rotational training programme)

\section{Results}

The questionnaire was completed by 41 respondents. The demographic details of the willing respondents are given in Table 1.

Table I : Demographic details of the respondents

\begin{tabular}{|c|c|c|}
\hline Persons approached & \multicolumn{2}{|l|}{65} \\
\hline Number of people who & \multicolumn{2}{|l|}{41} \\
\hline \multirow[t]{2}{*}{ consented to participate in study } & \multicolumn{2}{|c|}{27 males (65.9\%) } \\
\hline & \multicolumn{2}{|c|}{14 females $(34.1 \%)$} \\
\hline \multicolumn{3}{|l|}{ Religion } \\
\hline Hindu & 32 & $78.0 \%$ \\
\hline Christian & 3 & $7.3 \%$ \\
\hline Muslim & 2 & $4.9 \%$ \\
\hline Others & 4 & $9.8 \%$ \\
\hline \multicolumn{3}{|l|}{ Education } \\
\hline Below or upto std $10^{\text {th }}$ & 16 & $39 \%$ \\
\hline Till std $12^{\text {th }}$ & 15 & $36.6 \%$ \\
\hline Graduate & 8 & $19.5 \%$ \\
\hline Postgraduate & 2 & $4.8 \%$ \\
\hline
\end{tabular}

$78 \%$ of the respondents were aware of the concept of Organ donation while $22 \%$ had not even heard about it. Table 2 depicts the sources from where the respondents claimed to have obtained the necessary knowledge.

Table II : Depicts the sourcesfrom where the respondents claimed to have obtained the necessary knowledge regarding organ donation

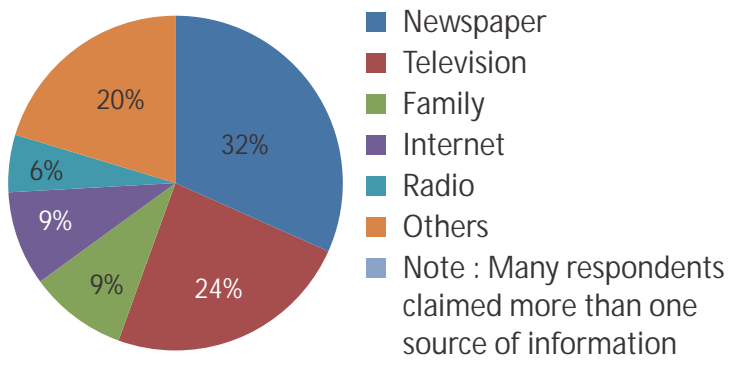

$26.8 \%$ who stated the source of information as "others" have specified it to be medical professionals such as doctors, nurses and other health care workers.

$39 \%$ of the respondents clearly stated that they had no idea regarding who can be an organ donor, $31.7 \%$ believed that organ donation is carried out after cardiac death, $24.4 \%$ were aware of live organ donation and only $14.6 \%$ were aware of organ donation following brain-death. Regarding knowledge of brain-death, $29.3 \%$ stated that brain-death involves loss of brain function and $31.7 \%$ felt that heart will continue to beat due to ventilator support in brain-dead individual. $7.3 \%$ only knew that brain-dead person is legally dead while $39 \%$ stated that they had no idea about braindeath.

Table 3 depicts the knowledge of the respondents regarding organs that can be donated.

Table III : Depicts the percentage of respondents with knowledge of various organs that can be donated

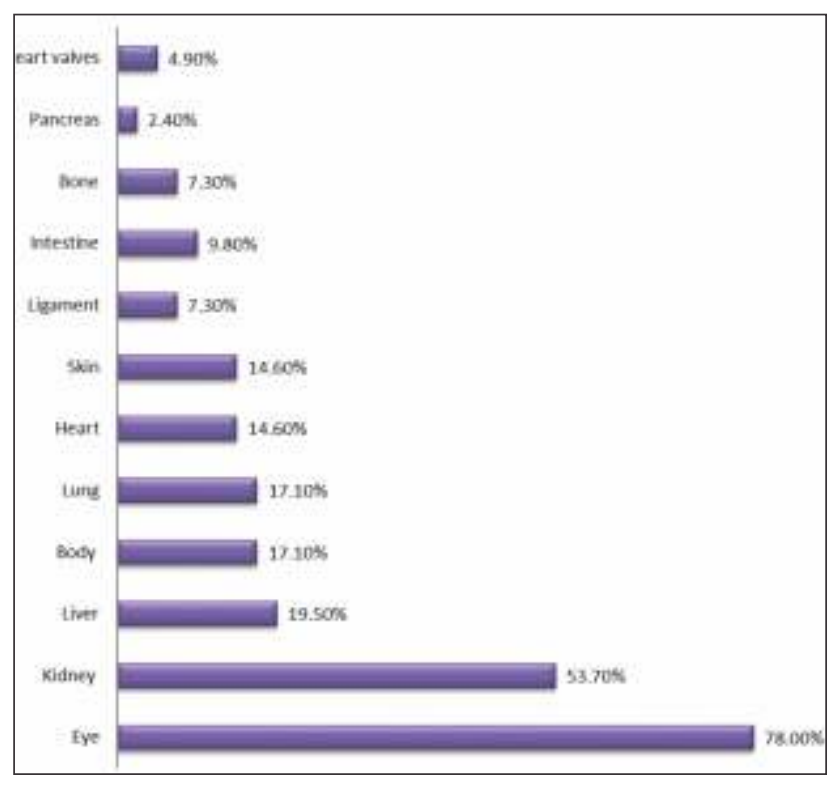

3 participants filled the body donation forms. $43.9 \%$ of the respondents were willing to be organ donors, $24.4 \%$ wanted to discuss the issue with family before taking the decision, $24.4 \%$ felt that they didn't know enough to take the decision and $4.9 \%$ did not wish to be organ donors at all.

Out of those who were willing to be donors, $72.2 \%$ of the respondents were willing to donate to unknown persons, $22 \%$ wished to donate only to their own family members and $11 \%$ to a M edical College. The commonest reason for refusal to be an organ donor was "fear that the donated organs may be misused" (50\%). $7 \%$ did not attempt the question. 
$83 \%$ of those consenting to be organ donors were followers of Hinduism while $17 \%$ were followers of Islam, Christianity and other religions. 53.7\% agreed to sign the donor card but only $29.3 \%$ actually signed it.

Some of the comments of the respondents were "I will make my family aware of my will, I don't care about what my religion says, I am not bothered. I am all for organ donation. Awareness needs to be created by constant supply of knowledge, presentations, dramas, lectures and some temple meetings will help", "After our death at least our organs continue to live", "Organ donation is a very good thing. Our act can make someone very happy" and "You should encourage those people who have achieved what they wanted to in life, I still have a lot to achieve, so sorry I cannot be a donor".

\section{Discussion}

Today, in India the demand for organs for transplantation far exceeds the supply. Transplant technology and surgical methods continue to improve enhancing chances of survival and improved quality of life for the recipient.[5] However this rapid enhancement in research pertaining to transplantation of organs has not been accompanied by a parallel increase in the availability of donor organs. There is a huge shortage of donor organs today all over the world. The success of deceased donor program in any region is dependent on the knowledge and attitude of the people residing in that region towards organ donation. [1] In the present study, authors have assessed the knowledge as well as attitude of patients and their relatives towards organ as well as body donation.

The participants in the present study were from urban region of Pune, a city in Western Maharashtra. The response to the questionnaire provided us with valuable insights into the understanding of the participants about organ and body donation.

M ost of the respondents were educated till standard $10^{\text {th }}$ and above. $41.5 \%$ and $31.7 \%$ of the respondents stated that newspaper and television were their sources of information regarding organ donation. The consistent role of media in spreading awareness is again emphasized by these findings which are similar to the finding reported by Bapat et al where newspaper and television were responsible for $60 \%$ of the knowledge propagation. M ovius et al stress on the role of media as an effective channel for communicating health related messages to increase knowledge.[6] Internet (12.2\%) is also fast immerging as an important source of knowledge dissemination. Many participants (12.2\%) claimed discussion within family as a source of information. Discussion within family has an additional benefit of dissemination of knowledge to all family members participating in the discussion and also prepares the family members for decisions taken by the person signing the donor card. Decision of one such member could encourage / inspire others also to follow suit. Many respondents specifically mentioned obtaining required knowledge from health care professionals. Health care professionals are the critical links in the organ procurement process because they are the first individuals to establish relationship with the potential donors' family. Education of health-care professionals in various aspects of organ donation is therefore a must as they in turn can propagate this knowledge at the community level.[7]

$31.7 \%$ of the respondents believed that organ donation is done after cardiac death. Actually only eyes, skin and other tissues can be donated after cardiac death today in India, though more and more organs are being transplanted after cardiac death all over the world. [8,9] $24.4 \%$ of the respondents were aware of live organ donation. India is ranked $2^{\text {nd }}$ in live organ donations in the world.[2] Wig et al in a study regarding awareness of brain death among people in a metro city found that awareness of the concept of brain death and its importance for organ donation was extremely low very few being aware that brain death is legal in India.[10] These findings are similar to finding in present study where only $7.3 \%$ knew that in India a braindead person is legally accepted as dead and $14.6 \%$ were aware of organ donation following brain-death. $29.3 \%$ stated that brain-death involves loss of brain function and $31.7 \%$ felt that heart will continue to beat due to ventilator support in a brain-dead individual but a very large 


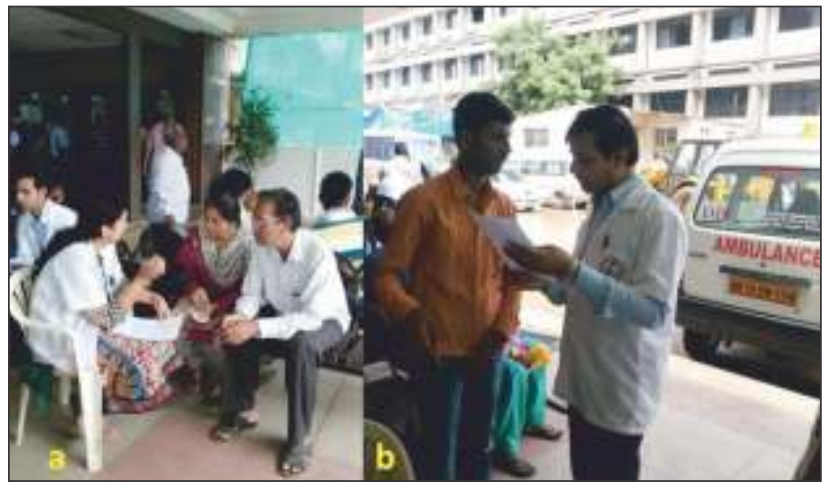

Figure $1(\mathbf{a}, \mathbf{b})$ : The photograph shows 2 of our researchers talking about the questionnaire with the respondents during Part I of the study.

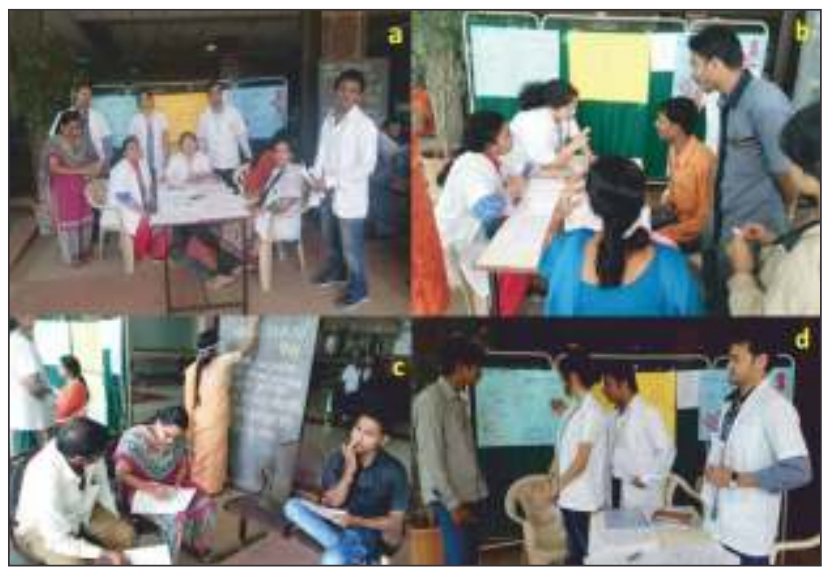

Figure $2(a, b, c, d)$ : These figures show the researchers during Part II of the study, (a) showing our team, $(b, c, d)$ showing team members discussing various aspects of Organ and Body donation with the respondents. Also seen in the background in (d) are the posters created by our interns which they can be seen explaining to one of the respondents.

percentage i.e. $39 \%$ stated that they had no idea about brain-death. Wig et al state that discussion with the grieving relatives regarding organ donation following brain-death, is very difficult.[10] If the relative is unfamiliar with the concept of organ donation following brain death, the discussion process becomes even more challenging. Awareness among relatives about the process of brain death and related organ donation and transplantation will ease the way for the discussion process. Dolatabadi et al carried out a before-after study about brain-death and organ donation on attitude and knowledge of the participants and found that the group which underwent educational session had a significant improvement in attitude and knowledge after the training session compared to the control group.[11] Thus educational sessions could be useful in increasing awareness levels regarding brain-death and it relevance from point of view of organ donation.

In the present study maximum awareness was found regarding donation of eyes (78\%), kidney (53.7\%) and liver (19.5\%). A 17.1\% awareness was also noted regarding both lung and body donations. 7.3\% respondents signed the body donation form. Awareness regarding all other organ donations ranged between 4 to $15 \%$.

In a study carried out by Priyadarshini B et al the incidence of awareness regarding eye donation was reported to be $50 \%$.[12] The present study reports a much higher $78 \%$. In a similar study carried out in Hubli city of Karnataka the incidence of awareness regarding eye donation was reported to be $96 \%$.[13] However the difference was the age of the respondents. While the average age of the respondents in the study carried out by Priyadarshini B was 55years, the study carried out by Nekar in Hubli was an awareness study among college students aged between 16-25 years.[12,13] Thus is awareness level greater in a younger age group in India? In the present study $59 \%$ of those who were aware of eye donation were below the age of 30 years. Thylefors et al state that a large proportion of the huge burden of blindness in India is avoidable.[14] Through corneal grafting it is possible to restore vision for a sizable proportion of the corneal blind in India. The Deputy Director General of National Programme for control of Blindness (India) stated in 2014 that there are about 0.12 million corneal blind persons in India today with about 20,000 being added to this number every year. Majority of these persons are young and their sight could be restored by a corneal transplantation. There are about 45,000 to 50,000 eyes being collected by sincere efforts of Eye Banks working in Government and Non-Government sector every year. But the actual need is for 0.12 million corneas. This gap of supply versus need can be met by creating mass public awareness and to encourage people to come forward and pledge their eyes for donation after their death.[15]

$22 \%$ of those respondents aware of kidney donation, were 
of the opinion that a living healthy person can be a donor. Another $22 \%$ believed that the donor could be brain dead person, but $32 \%$ believed that the donor had to be cardiac dead person. The rest of the respondents, while being aware of kidney donations and transplants, professed lack of knowledge regarding the health condition of the donor. Thus it appears that though there is awareness regarding kidney donations to day, there is lack of clarity as to who can donate the organ. A person who is willing to donate, but unclear about the health status of the donor, might inform hisfamily of his will to be a kidney donor. On the event of his death, the family in good faith may call the hospital authorities informing them of the demise. However with the donor being cardiac-dead, he/she would not qualify to be a kidney donor resulting in the wishes of the said donor remaining unfulfilled and the family feeling disappointed. Such experiences can be avoided by carrying out awareness programs which explain not only the need for kidney and other organ donations, but also the details of the health status of the donor including when organ donation is contraindicated.

In the present study only $4.9 \%$ of the respondents were unwilling to be organs donors. All the others were either willing(43.9\%), wanting to discuss the issue with family before taking the decision(24.4\%) or felt need to know more before taking the decision (24.4\%). The comments by the respondents were witness to their willingness to be donors and reasons for the same. Ability to live even after one's death and give someone immense happiness was observed to be a driving factor for organ donation. The comment regarding approaching someone who has achieved all they wish to in life for organ donation, however depicts the lack of understanding regarding organ donation which happens mostly after brain-death.In a study by Annadurai et al $12.5 \%$ were willing to be donors, $19.8 \%$ would only donate under special circumstances, $43 \%$ wanted to think about it and $16.8 \%$ would never even consider doing organ donation.[16] Thus in the present study the percentage of respondents completely unwilling to be donors was found to be lesser than the findings in the study by Annadurai et al. However in both the studies, above $50 \%$ of the respondents were in undecided state of mind.

Fear that the donated organ may be misused was the reason cited by $50 \%$ of those respondents who were unwilling to be donors. Khan et al also observed that people who could be donors, are reluctant to donate due to lack of knowledge and fear of the organ being misused.[17] They further state that adequate awareness sessions with a multi-sectoral approach i.e. through electronic media, print media, doctors, teachers and religious scholars could help in dissemination of correct knowledge and remove this fear from minds of potential donors. Morgan et al stated that Medical mistrust is the most frequently cited reason for not wanting to be a donor.[18] M edical mistrust included fear that doctors might declare death prematurely to procure organs and doubts regarding equity in organ allocation system.

At this point, the authors would like to state that out of the 65 patients approached, only 41 agreed to participate in the present study. $100 \%$ of those who refused to participate in the study, believed that consenting to participate in the study and thus signing the consent form, meant signing to be an organ donor in future. Despite explaining the consent form for the study in detail, 24 individuals refused to be part of the study for the same reason. This was a different type of medical mistrust observed in the present study compared to that observed by M organ et al.[18]

$53.7 \%$ agreed to sign the donor card but only $29.3 \%$ actually signed it. This discrepancy is difficult to explain and needs a psychological explanation.

Scope of the study is that we would like to carry out the same study in the rural population, so as to compare attitudes and knowledge levels between the rural and urban populations.

\section{Conclusion}

Donated organs transplanted into patients suffering from end stage organ failure has changed the course of many illnesses today. However the crucial factor is availability of a 
donor for which there has to be awareness. The present study not only assessed the level of awareness among the people but also discussed various aspects of organ and body donation with the respondents.

The study reported that newspaper, television and healthcare workers are most effective in providing knowledge of organ and body donation to the people. It can be concluded that these could be used effectively to further the message of organ and body donation among the people.

While $78 \%$ of respondents were aware of organ and body

\section{References}

1. Bapat U, Kedlaya PG, Gokulnath. Organ donation, awareness, attitudes and beliefs among post graduate medical students. Saudi J Kidney Dis Transpl 2009;20(1):174-80

2. Khanna U.The Economics of Dialysis in India.Indian Journal of Nephrology 2009;19(1):1-4

3. Ajita R,Singh YL.Body Donation and its relevance in Anatomy:A Review.J Anat.Soc.India 2007;56(1):44-47.

4. Alghanim SA.Knowledge and Attitudes toward Organ Donation: A Community-Based Study Comparing Rural and Urban Populations.Saudi] Kidney Dis Transpl 2010;21(1):23-30.

5. Watson CJE,Dark JH.Organ Transplantation:Historical Perspective and current practice.British Journal of Anaesthesia 2012;108(s1):i29-i42.

6. Movius L,Cody M,Huang G,Berkowitz M,Morgan S.Motivating Television Viewers to become Organ donors.Cases in Public Health Communication and marketing.2007 June.Available from:http:// www.casesjournal.org/volume1/peer-reviewed/cases_1_08.cfm

7. Schaeffner ES,Windisch W,Friedel K,Bruitenfeldt K,Winkelmayer WC. Knowledge and attitude-organ donation among medical students and physicians. Transplantation 2004;77(11):1714-8.

8. Detry O,Le Dinh H,Noterdaeme T,De Roover A,Squifflet JP,M eurisse M.Categories of Donation after Cardiocirculatory Death. Transplantation Proceedings 2012;44(5):1189-95.

9. Gopalkrishnan G,Gourabathini. M arginal Kidney donor.Indian Journal of Urology.2007;23(3):286-293.

10. Wig N,Gupta P, Kailash S. Awareness of Brain Death and Organ Transplantation Among Select Indian Population.JAPI 2003;51:455- donation, very few were aware of the necessary health status of the donor. 39\% had no awareness regarding concept of brain-death.

$43.9 \%$ respondents were willing to donate and about $48 \%$ were undecided. These $48 \%$ are a very large percentage of people who on effective dissemination of knowledge could be convinced to be donors. Reason for unwillingness to be a donor was "fear of misuse of donated organ by the medical personnel". Stringent laws and open organ allotment system could remove this fear from the minds of the people to further increase the number of organ donors.

58.

11. Dolatabadi ZA, Farahani B,Fesharaki M,Najafizadeh K.Effect of education about brain-death and organ donation on attitude and knowledge of nursing students.Iranian Journal of Critical Care Nursing.2010;3(3):109-112.

12. Priyadarshini B,Srinivasan M,Padmavathi A,Selvam S,Saradha R,Nirmalan P.Awareness of Eye Donation in an adult Population of Southern India.A Pilot Study.Indian J Ophthalmol 200351:101-104

13. Nekar M, Lokare L,Gokhale S,Godbole M,Mulkipatil SY,Mahesh V.Awareness of Eye donation among College students of Hubli city, Karnataka.IJBR 2012;3(04):201-204.

14. Thylefors B,Negrel AD,Pararajasegaram R,Dadzie KY.Global data on Blindness.Bulletin of the World Health Organization.1995;73(1):115121.

15. Observance of 29th National Fortnight on Eye Donation from 25th August to 8th September 2014 under National Program for control of Blindness. http://npcb.nic.in/writereaddata/mainlinkfile/File314.pdf

16. Annadurai K,M ani K,Ramasamy J.A study of knowledge, attitude and practices about organ donation among college students in Chennai,Tamil Nadu-2012.Prog Health Sci 2013;3(2):59-65

17. Khan N,M asood Z,Tufail N,Shoukat H,Ashraf KTA,Ehsan S,Zehra S,Battol N,Akram S,Khalid S.Knowledge and Attitude of people towards Organ Donation.JUM DC 2011;2(2):15-21.

18. M organ S,Harrison TR.In their own words:The reasons why people will (not) sign a donor card.Health Communication 2008;23:23-33. 